\title{
PERSPECTIVE FOR PHARMACEUTICAL INNOVATION IN BRAZIL - CENTER FOR APPLIED TOXINOLOGY (CEPID- Center for Research, Innovation and Dissemination - FAPESP)
}

\begin{abstract}
The Center for Applied Toxinology (CAT), an institutional research organization based at the Butantan Institute, is one of the several Centers of Research, Innovation and Dissemination (CEPID) created in September 1998. CEPID, a pioneering program of the The State of São Paulo Research Foundation (FAPESP), was established to stimulate research, disseminate knowledge and foster contact between science and industry. CAT aims at conducting research on compounds derived from naturally occurring toxins, which might be of medical, ecological and economic interest. CAT takes a multidisciplinary approach in the investigation of natural toxins, including isolation and purification, pharmacological action, structural determination, structure-function studies, and molecular biology aspects. The following institutions will be involved in this endeavor: University of São Paulo (USP) [Marine Biology Center; Departments of Physiology and Anatomy, Institute for Biomedical Sciences; Department of Biochemistry, Institute of Chemistry]; São Paulo State University (UNESP) [Laboratory of Structural Biology and Zoochemistry, Institute of Biosciences, Rio Claro; Laboratory of Crystallography, Department of Physics, Institute of Biosciences, Humanities, and Exact Sciences, São José do Rio Preto]; and the Federal University of São Paulo (UNIFESP).
\end{abstract}

Antonio Carlos Martins de Camargo

Coordinator of the Center for Applied Toxinology (CEPID - Center for Research, Innovation and Dissemination - FAPESP). Instituto Butantan, Avenida Vital Brasil, 1500, 05503-900, São Paulo - SP, Brasil. Email: acmcamargo@butantan.gov.br 


\section{PERSPECTIVE FOR PHARMACEUTICAL INNOVATION IN BRAZIL - CENTER FOR APPLIED TOXINOLOGY (CEPID - Center for Research, Innovation and Dissemination - FAPESP)}

The Center for Applied Toxinology (CAT), an institutional research organization based at the Butantan Institute, is one of the several Centers of Research, Innovation and Dissemination (CEPID) created in September 1998. CEPID, a pioneering program of the The State of São Paulo Research Foundation (FAPESP), was established to stimulate research, disseminate knowledge and foster contact between science and industry.

CAT aims at conducting research on compounds derived from naturally occurring toxins, which might be of medical, ecological and economic interest.

Why natural toxins? Toxins appear as constituents of venoms, secretion and components from a variety of animal, plant, and microbial sources. Toxins are used for defensive purposes or as means of attack. They exert their effects by acting on a variety of targets, including cardiovascular, inflammation, pain, paralysis, death, etc. Studying these effects should lead to a better understanding of control mechanisms in these systems. Toxins can be valuable tools for biochemical and pharmacological research. They can also serve as lead compounds in new drug development, thus transferring toxicity into potential benefit. A significant fraction of medication currently in use derived directly or indirectly from natural toxins.

CAT takes a multidisciplinary approach in the investigation of natural toxins, including isolation and purification, pharmacological action, structural determination, structurefunction studies, and molecular biology aspects. The following institutions will be involved in this endeavor: University of São Paulo (USP) [Marine Biology Center; Departments of Physiology and Anatomy, Institute for Biomedical Sciences; Department of Biochemistry, Institute of Chemistry]; São Paulo State University (UNESP) [Laboratory of Structural Biology and Zoochemistry, Institute of Biosciences, Rio Claro; Laboratory of Crystallography, Department of Physics, Institute of Biosciences, Humanities, and Exact Sciences, São José do Rio Preto]; and the Federal University of São Paulo (UNIFESP). 
A. C .M. Camargo. PERSPECTIVE FOR PHARMACEUTICAL INNOVATION IN BRAZIL - CENTER FOR APPLIED TOXINOLOGY (CEPID - Center for Research, Innovation and Dissemination - FAPESP) J. Venom. Anim. Toxins incl. Trop. Dis., 2005, 11, 4, p. 385

Research findings stemming from CAT resulted in the filing of eight patents and transferring to drug development in collaboration with three Brazilian pharmaceutical companies: Biolab/Sanus, Biosintética, and União Química. Recently, another Brazilian Pharmaceutical Industry, Cristália, joined us. Furthermore, Fapesp is evaluating the establishment of a partnership with Merck, Sharp and Dohme (England). It is our hope that a genuinely national pharmaceutical or biotechnology company will emerge from research pursued at the Center.

Scientific literacy is the bedrock foundation for economic development of a country. CAT will be deeply involved in a toxin-related bioliteracy. Courses will be offered in classrooms, in the field, and also via Internet, covering subjects on both terrestrial and marine venomous animals, on toxins from plants and microorganisms, on accident and disease prevention, on health-related problems, and on ecological preservation and Nature conservation. Besides Butantan Institute, the following institutions will be involved in this program: USP (Faculty of Education, Zoology Museum), UNESP (Rio Claro and Rio Preto) and UNIFESP. Brazil with its particular natural diversity is uniquely suited for exploitation and contribution to the field of toxinology.

\section{BACKGROUND}

Snakebite has always been a major health problem in Brazil. Historically, toxin research in the country has been driven by concerns for public health and safety, not only from snakebite, but also from insect bites and pathogenic microorganisms. The major toxic manifestations and symptoms of snake and insect bites can be ascribed to coagulant, hemorrhagic, myotoxic, neurotoxic and/or proteolytic activities of these venoms. These activities, because of the ready access to snake toxins, have attracted a sizeable number of investigators in Brazil. However there is not enough interaction between disciplines and groups and there exists a tendency towards dispersion of efforts. For toxinology to develop into a strong field in Brazil, it is imperative that there be more cooperation between groups and greater integration of their efforts.

Studies will start with already ongoing research on toxins from organisms and microorganisms of interest. This first step in the project will be followed by the concerted activities of several institutions. 
A. C .M. Camargo. PERSPECTIVE FOR PHARMACEUTICAL INNOVATION IN BRAZIL - CENTER FOR APPLIED TOXINOLOGY (CEPID - Center for Research, Innovation and Dissemination - FAPESP) J. Venom. Anim. Toxins incl. Trop. Dis., 2005, 11, 4, p. 386

\section{RESEARCH}

Research at the Center will focus on the following topics:

a) Antihypertensive and vasodilator drugs. In Brazil, researchers in the field of toxinology have carried out the isolation and purification of venom fractions and studied their pharmacological activities. Among these studies, one that had a great impact was Maurício Rocha e Silva's discovery of bradykinin in 1949. Bradykinin is released from proteins in blood plasma by the action of a protease found in the venom of the snake Bothrops jararaca. Bradykinin is a potent vasoactive peptide that causes pain, vasodilation, and increased vascular permeability. This work stimulated research in the area of kinins and inflammation. In 1965, one of Rocha e Silva's students, S.H. Ferreira, discovered, in the same B. jararaca venom, the presence of a group of hypotensive peptides, which are angiotensin-converting enzyme inhibitors. This finding greatly influenced the field of vasoactive peptide research. These inhibitors served as the lead compound for the synthesis of captopril by Squibb (USA) in 1977. Antihypertensive substances occur as components of various animal venoms. Besides carrying out gene analysis of these substances, the Center will look for better antihypertensive and vasodilator drugs, such as maxadilan, the most potent vasodilator known that is found in the sandfly Lutzomyia longipalpis.

b) Anticoagulant factors. Many compounds with activities interfering with the hemostasis can be identified in reptile and arthropod venoms. These compounds are of interest as tools for the understanding of hemostatic mechanisms and as potential therapeutic agents.

c) Neurotoxins. Several glutamate antagonists have been found in nature. Recently, with the development of improved analytical method and because of the interesting neurotoxic activities of these compounds, the polyamine components of spider as well as wasp venoms have attracted increasing attention. Until recently, natural toxins have not played a major role in probing the biochemistry and pharmacology of calcium-ion channels. A family of peptides from predatory cone snails has provided a series of powerful blockers of calcium-ion channels. Venom of the funnel-web spider, as well as of honeybee, also contains a series of calcium-ion-channel blockers. Brazilian coastal waters, extending for 5,000 miles, have been poorly explored for the 
A. C .M. Camargo. PERSPECTIVE FOR PHARMACEUTICAL INNOVATION IN BRAZIL - CENTER FOR APPLIED TOXINOLOGY (CEPID - Center for Research, Innovation and Dissemination - FAPESP) J. Venom. Anim. Toxins incl. Trop. Dis., 2005, 11, 4, p. 387

isolation of bioactive substances from marine organisms. The Center will make an effort to strengthen this field of research.

d) Amphibian skin secretion. Many bioactive compounds have been described in the skin secretions of amphibians, including several biogenic amines, sterols, alkaloids, peptides and proteins, with a large variety of biological actions. The occurrence of different toxins in skin secretions has been ascribed to two defense mechanisms: one against predators and the other against the growth of microorganisms. Skin secretions from an amphibian, which the Brazilian Mayoruna Indians introduce into their bodies through fresh burns, are rich in peptides. These include vasoactive peptides, such as sauvagine, opioid peptides, as well as adenoregulin and related peptides that affect behavior.

e) Bacterial enterotoxins. In Brazil, health problems are extremely critical, especially due to unsatisfactory sanitary conditions prevailing throughout the country and poor welfare policies. Mortality of children under 5 years fluctuates between 50 and 70/1000, diarrheal diseases being one of the main causes. The Microbiology Laboratory of the Butantan Institute is one of the leading centers of research in the field of enteric bacterial toxins. Besides carrying out basic research in this area, it is involved in the process of developing immunological techniques to be used in food industry for the detection of enterotoxins.

\section{EDUCATIONAL ACTIVITIES}

Since its beginning, Butantan Institute has been involved in scientific and technological development related to animal and microbial toxins and the production of immunobiologicals to these agents.

In the early days of higher education in Brazil, the Institute offered excellent conditions for the training and certification of research scientists in this field. For the past several decades, Butantan Institute has been actively involved in cultural and educational areas. The Biological Museum exhibits both live and preserved specimens to about half a million visitors a year. The Herpetological Collection harbors some 60,000 snake specimens and serves as a center for study of the distribution, taxonomy and evolution of snakes. 
A. C .M. Camargo. PERSPECTIVE FOR PHARMACEUTICAL INNOVATION IN BRAZIL - CENTER FOR APPLIED TOXINOLOGY (CEPID - Center for Research, Innovation and Dissemination - FAPESP) J. Venom. Anim. Toxins incl. Trop. Dis., 2005, 11, 4, p. 388

The Institute, through its Division of Cultural Development and Museum, offers extension courses to about 2,000 students a year, covering venomous animals, antivenom-sera and vaccines, insects of medical importance, biology of amphibian and molecular biology. All these courses are given at different levels, for school children, teenagers and the general public, undergraduate and graduate students, teachers and professionals. These courses have greatly contributed to inspiring young students in this field.

From the public health point of view, there is a strong necessity of adding health related courses. Therefore, educational program will be expanded to include pathogenic microorganisms and viruses, with emphasis in hygiene, disease prevention and biodiversity conservation. The Center is planning to start a graduate course in Medical Biotechnology. The aim is to prepare highly qualified professionals in the area related to the development of new pharmaceutical and/or agrochemical products by modern biotechnological processes.

\section{TECHNOLOGY TRANSFER}

There is little technological development outside an active, high quality, basic scientific research environment that trains qualified personnel, stimulates brainpower and fosters innovative thinking. A country may, if it so decides, build scientific and technical capabilities, but the maturation of such an effort requires time and continuity.

In Brazil, communication between academia and industry leaves much to be desired. Many factors have contributed to this. Among them:

1. Inherent lack of an appreciation for business by members of the scientific community. This attitude reflects the absence of a serious national policy on scientific and technological development;

2. Brazilian companies do not have sufficient resources to invest in sophisticated scientific research; consequently, technology is transplanted - the "know-how" but, unfortunately, not the "know-why";

3. Multinationals dominate almost all branches of the industry in Brazil but concentrate on marketing, leaving $R \& D$ to be done in their home countries;

4. There is, practically, no national venture capital. Foreign capital is not interested in a weak scientific-technological establishment, except when 
A. C .M. Camargo. PERSPECTIVE FOR PHARMACEUTICAL INNOVATION IN BRAZIL - CENTER FOR APPLIED TOXINOLOGY (CEPID - Center for Research, Innovation and Dissemination - FAPESP) J. Venom. Anim. Toxins incl. Trop. Dis., 2005, 11, 4, p. 389

processes must be developed on the spot and provide rapid returns, as is the case in agriculture;

5. The mentality prevailing since colonial times of taking quick profits without reinvesting in modern production methods.

In order to fill the competence gap in the area of product development, cooperation between research institutions and pharmaceutical/biotechnology corporations is needed. This is also true for the highly specialized areas of screening drugs and clinical test.

Drug development will be carried out in collaboration with the consortium of the following pharmaceutical companies: Biolab/Sanus, Biosintética and União Química.

\section{JUSTIFICATION}

Recent progress witnessed in the field of toxinology is due to advance in isolation techniques and spectroscopy for structural determination, allowing the accomplishment of this task with a minute quantity of samples. These improvements have resulted in intense studies on structure-biological activity relationships and many toxins have become useful tools for the elucidation of these mechanisms. This progress, combined with new methodological approaches, has greatly contributed to the burgeoning and upsurging of modern toxinology. Consequently, pharmaceutical and agrochemical companies have shown a great interest in natural toxins for the purpose of using them as lead-compounds for the design of new drugs. This trend can be seen in the current number and types of applications registered in the US Patent \& Trademark Office, based on venom toxins from various organisms: snake 154 , spider -28 , scorpion - 16 , and wasp -4 . These applications include new drugs for neurodegenerative and cardiac diseases, immunosuppressants, diagnostic reagents, selective bioinsecticides, and scientific tools.

Thus, it is clear the potential of toxins as the "source of inspiration" for the rational development of novel drugs for different clinical targets. A substantial fraction of medicines currently in use were, directly or indirectly, derived from natural toxins produced by venomous animals, plants or microorganisms. Brazil is the synonym of biodiversity and biodiversity means chemical diversity. Considering the presence of innumerable insects and animals with still uncovered chemical weapons, this is one 
A. C .M. Camargo. PERSPECTIVE FOR PHARMACEUTICAL INNOVATION IN BRAZIL - CENTER FOR APPLIED TOXINOLOGY (CEPID - Center for Research, Innovation and Dissemination - FAPESP) J. Venom. Anim. Toxins incl. Trop. Dis., 2005, 11, 4, p. 390

field in which Brazil can contribute in a unique way to its development. Partly due to this regional advantage, the field of toxinology has a long tradition in this country. Considering the critical mass of highly qualified researchers gathered from various institutions for the execution of the project, it is realistic to expect the development of new drugs. It is our earnest hope that a genuinely national pharmaceutical/biotechnology company may emerge from research pursued at the Center for Applied Toxinology.

\section{Antonio Carlos Martins de Camargo}

Coordinator of the Center for Applied Toxinology (CEPID - Center for Research, Innovation and Dissemination - Fapesp). E-mail: acmcamargo@butantan.gov.br 